\title{
Association between mean arterial pressure during the first 24 hours and hospital mortality in patients with cardiogenic shock
}

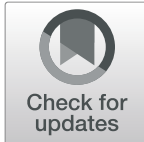

Barry Burstein ${ }^{1}$, Meir Tabi ${ }^{2}$, Gregory W. Barsness ${ }^{2}$, Malcolm R. Bell ${ }^{2}$, Kianoush Kashani ${ }^{1,3}$ and Jacob C. Jentzer ${ }^{1,2,4^{*}}$ (D)

\begin{abstract}
Background: The optimal MAP target for patients with cardiogenic shock (CS) remains unknown. We sought to determine the relationship between mean arterial pressure (MAP) and mortality in the cardiac intensive care unit (CICU) patients with CS.
\end{abstract}

Methods: Using a single-center database of CICU patients admitted between 2007 and 2015, we identified patients with an admission diagnosis of CS. MAP was measured every $15 \mathrm{~min}$, and the mean of all MAP values during the first $24 \mathrm{~h}\left(\mathrm{mMAP}_{24}\right)$ was recorded. Multivariable logistic regression determined the relationship between $\mathrm{mMAP}_{24}$ and adjusted hospital mortality.

Results: We included 1002 patients with a mean age of $68 \pm 13.7$ years, including $36 \%$ females. Admission diagnoses included acute coronary syndrome in $60 \%$, heart failure in $74 \%$, and cardiac arrest in $38 \%$. Vasoactive drugs were used in $72 \%$. The $\mathrm{mMAP}_{24}$ was higher $(75 \mathrm{vs.} 71 \mathrm{mmHg}, p<0.001$ ) among hospital survivors (66\%) compared with non-survivors (34\%). Hospital mortality was inversely associated with mMAP 24 (adjusted OR 0.9 per $5 \mathrm{mmHg}$ higher $\mathrm{mMAP}_{24}, p=0.01$ ), with a stepwise increase in hospital mortality at lower mMAP 24 . Patients with $\mathrm{mMAP}_{24}<65 \mathrm{mmHg}$ were at higher risk of hospital mortality (57\% vs. 28\%, adjusted OR 2.0, 95\% Cl 1.4-3.0, $p<$ 0.001); no differences were observed between patients with $\mathrm{mMAP}_{24} 65-74 \mathrm{vs}$. $\geq 75 \mathrm{mmHg}(p>0.1)$.

Conclusion: In patients with $C S$, we observed an inverse relationship between $\mathrm{mMAP}_{24}$ and hospital mortality. The poor outcomes in patients with $\mathrm{mMAP}_{24}<65 \mathrm{mmHg}$ provide indirect evidence supporting a MAP goal of 65 $\mathrm{mmHg}$ for patients with CS.

Keywords: Cardiogenic shock, Shock, Cardiac intensive care unit, Critical care, Mortality, Hypotension, Blood pressure

\section{Background}

Cardiogenic shock (CS) is the second-most common form of circulatory shock in all critical care units and the most common form of shock among patients admitted to cardiac intensive care units (CICUs) $[1,2]$. CS manifests in clinical, hemodynamic, and biochemical derangements characterized by arterial hypotension and

\footnotetext{
* Correspondence: jentzer.jacob@mayo.edu

${ }^{1}$ Division of Pulmonary and Critical Care Medicine, Mayo Clinic, Rochester, MN, USA

2Department of Cardiovascular Medicine, Mayo Clinic, Rochester, MN, USA Full list of author information is available at the end of the article
}

tissue hypoperfusion, resulting in significant morbidity and mortality despite appropriate treatment [3]. The mainstay of management is early intervention to address the inciting cause, in conjunction with supportive care, to restore end-organ perfusion and prevent multi-organ failure and death [3]. In cases of acute myocardial infarction, emergency revascularization is indicated in order to improve cardiac function [4].

Immediate restoration of adequate systemic blood pressure using intravenous inotropes, vasopressors, and/ or mechanical circulatory support is a priority in CS [3]. 
The optimal blood pressure target in CS must balance the maintenance of adequate end-organ perfusion with the adverse effects of excessive cardiac afterload and arrhythmias induced by catecholamine vasopressors. The ideal target mean arterial pressure (MAP) for patients with CS is unclear, and current strategies are based on evidence from patients with vasodilatory shock and cardiac arrest (CA) $[3,5,6]$. Furthermore, it has been suggested that patients with pre-existing hypertension may benefit from higher MAP goals [7], and a history of hypertension is common among patients with cardiovascular disease [8]. By contrast, recent evidence has demonstrated favorable outcomes among older patients supported with permissive hypotension (MAP 60-65 mmHg) [9].

Given the sparsity of evidence to support specific MAP targets in patients with CS, we sought to describe the relationship between MAP and hospital mortality among patients with CS. We hypothesized that hospital mortality among patients with CS would increase as a function of lower MAP and that a threshold MAP may identify an optimal MAP range. Our secondary aim was to evaluate the prevalence of organ failure as a function of MAP.

\section{Methods}

\section{Study population}

This study was approved by the Institutional Review Board of Mayo Clinic (IRB \# 16-000722) as posing minimal risk to patients and was performed under a waiver of informed consent. We retrospectively analyzed a database containing data from the initial CICU admission for consecutive unique adult patients aged $\geq 18$ years admitted to the CICU at Mayo Clinic Hospital St. Mary's Campus between January 1, 2007, and December 31, 2015 [10-12]. The Mayo Clinic CICU is a closed unit serving critically ill cardiac medical patients, but not postoperative cardiac surgery patients and patients receiving extracorporeal membrane oxygenation (ECMO) support. We included only those patients with an admission diagnosis of CS, defined as an International Classification of Diseases (ICD)-9 code of 785.51 documented within 1 day of CICU admission. We excluded all patients without an admission diagnosis of CS (including those without available admission diagnosis data), even if they had an ICD-9 code for CS documented at another time during hospitalization. Patients without available data on MAP were also excluded. Patients who declined Minnesota Research Authorization, according to Minnesota state law statute 144.295, were excluded from the study.

\section{Data sources}

We recorded demographic, vital sign, laboratory, clinical, and outcome data, as well as procedures and therapies performed during the $\mathrm{CICU}$ and hospital stay, as previously described [10-12]. All relevant data were extracted electronically from the medical record using the Mayo Clinic Multidisciplinary Epidemiology and Translational Research in Intensive Care Data Mart [13]. The admission value of all vital signs, clinical measurements, and laboratory values was defined as either the first value recorded after CICU admission or the value recorded closest to CICU admission. In addition, vital signs were recorded every $15 \mathrm{~min}$, and the maximum, minimum, and mean values over the first 1,6 , and $24 \mathrm{~h}$ were recorded. Blood pressure was preferentially recorded from invasive measurements, when available, and otherwise was recorded from noninvasive measurements. Peak vasopressor and inotrope doses were used to calculate the Vasoactive-Inotropic Score [14]. Admission diagnoses included all ICD-9 diagnostic codes recorded on the day of CICU admission and the day before or after CICU admission; these admission diagnoses were not mutually exclusive, and the primary admission diagnosis could not be determined. Admission diagnoses of interest included CS, acute coronary syndrome (ACS), heart failure (HF), supraventricular tachycardia, atrial fibrillation, ventricular fibrillation, ventricular tachycardia, CA, respiratory failure, and sepsis. Discharge ICD-9 diagnostic codes were reviewed for a diagnosis of hypertension. Severe acute kidney injury (AKI) was defined as KDIGO stage 2 or 3 AKI during the CICU stay (i.e., doubling of serum creatinine or increase in serum creatinine to $\geq 4.0 \mathrm{mg} / \mathrm{dl}$ or new dialysis initiation in the CICU); mild AKI was defined as KDIGO stage 1 AKI (an increase in creatinine by $\geq 0.3 \mathrm{mg} / \mathrm{dl}$ or $50 \%$ from baseline) $[11,15]$. Baseline creatinine was considered to be the latest creatinine within 1 year prior to the index hospital admission, and patients who had previously received dialysis were excluded from this AKI analysis. Non-cardiovascular organ failure was defined as a score $\geq 3$ on any day 1 SOFA organ subscore [16].

\section{Statistical analysis}

The primary endpoint was all-cause hospital mortality; secondary endpoints included CICU mortality and postdischarge mortality up to 1 year among hospital survivors. Mortality and other outcome data were extracted from Mayo Clinic electronic databases, the state of Minnesota electronic death certificates, and the Rochester Epidemiology Project database [17]. Categorical variables are reported as number (percentage), and the Pearson chi-squared test was used to compare groups. Continuous variables are reported as mean $( \pm$ standard deviation); the Wilcoxon rank-sum test was used to compare groups. The calculation of 24 -h mean MAP $\left(\mathrm{mMAP}_{24}\right)$ was performed using invasive blood pressure measurements, if available; otherwise, $\mathrm{mMAP}_{24}$ was calculated using noninvasive blood pressure values. Logistic 
regression was used to determine the association between mMAP $_{24}$ with hospital mortality before and after adjusting for age, gender, race, Charlson Comorbidity Index (CCI), and Acute Physiology and Chronic Health Evaluation IV (APACHE-IV) predicted mortality; admission diagnoses of CA, sepsis, HF, and ACS; peak 24-h VIS; and the use of intra-aortic balloon pump (IABP), dialysis, pulmonary artery catheter (PAC), coronary angiography, percutaneous coronary intervention (PCI), and mechanical ventilation. Subgroup analysis was performed by repeating multivariable logistic regression after excluding patients with SCAI shock stages A or B or sepsis; besides, logistic regression was repeated in the overall cohort after adjusting for SCAI shock stages. Discrimination was assessed using the area under the receiver-operator characteristic curve (AUC, $c$-statistic) value, and the optimal cutoff defined using Youden's $J$ index. Post-discharge survival among hospital survivors was evaluated using the Kaplan-Meier survival analysis and Cox proportional-hazards analysis. Two-tailed $p$ values $<0.05$ were considered statistically significant. Statistical analyses were performed using JMP Pro version 14.1.0 (SAS Institute, Cary, NC).

\section{Results}

\section{Study population}

The database included 10,004 unique CICU patient admissions, of whom 1078 had an admission diagnosis CS and were potentially eligible for inclusion [10]. We excluded 76 of these patients due to lack of available data for MAP (Supplemental Figure 1). The final study population of 1002 unique patients had a mean age of $67.7 \pm$ 13.7 years, including $36.4 \%$ females (Table 1 ). The mean CCI was $2.4 \pm 2.5$, and the mean APACHE-IV predicted hospital mortality was $38.4 \% \pm 29.3$ overall. Concomitant admission diagnoses included ACS in 599 (59.8\%) patients, HF in 740 (73.9\%), sepsis in 199 (19.9\%), and CA in 379 (37.8\%); 77 (7.7\%) patients had neither ACS nor $\mathrm{HF}$ as an admission diagnosis. Non-cardiovascular organ failure developed on the first day in 690 (68.9\%) patients; 630 (73.2\%) patients developed AKI during the CICU stay, including 314 (36.5\%) with severe AKI.

The mMAP $_{24}$ for the population was $73.4 \pm 10.1 \mathrm{mmHg}$. A total of $186(18.6 \%)$ patients had a mMAP $_{24}<65$ $\mathrm{mmHg}$, and $390(38.9 \%)$ patients had a $\mathrm{mMAP}_{24} \geq 75$ mmHg. During the first $24 \mathrm{~h}$ of the CICU stay, 719 (71.8\%) patients received vasoactive drugs, including vasopressors in 668 (66.7\%), and inotropes in $282(28.1 \%)$, with a mean peak 24-h VIS of $26.1 \pm 54.3$. IABP was used during the CICU admission in 389 (38.8\%) of patients.

Patients with a mMAP $24<65 \mathrm{mmHg}$ differed from patients with a mMAP $2465-75 \mathrm{mmHg}$ or mMAP $_{24} \geq 75$ $\mathrm{mmHg}$ (Table 1), with greater severity of illness (APAC HE-III score $100.8 \pm 35.3$ vs. $87.5 \pm 32.0$ vs. $77.9 \pm 30.2$, $p<0.001)$, more severe CS based on Society for Cardiovascular Angiography and Interventions (SCAI) staging, increased incidence of severe AKI (30.0\% vs. $19.8 \%$ vs. $14.8 \%, p=0.001$, Fig. 1a), greater use of vasoactive infusions $(85.5 \%$ vs. $78.9 \%$ vs. $54.4 \%, p<0.001)$, and an increased number of non-cardiac organ injury (mean 1.4 vs. 1.1 vs. $0.9,<0.001$, Fig. $1 \mathrm{~b}$ ). Conversely, patients with mMAP $_{24}<65 \mathrm{mmHg}$ underwent fewer coronary angiograms $(52.5 \%$ vs. $64.6 \%$ vs. $70.5 \%, p<0.001)$ and were less often supported with an IABP or Impella device (Abiomed, Danvers, MA, USA) $(30.1 \%$ vs. $50.5 \%$ vs. $46.4 \%$, respectively, $p<0.001$ ).

\section{Hospital mortality}

Hospital mortality was $33.7 \%$, including $23.4 \%$ of patients who died in the CICU. Patients who died in the hospital had lower $\mathrm{mMAP}_{24}$ (70.8 vs. $74.7 \mathrm{mmHg}, p<$ $0.001)$. Crude hospital mortality was higher in patients with mMAP $_{24}<65 \mathrm{mmHg}$ compared with patients with mMAP $_{24} 65-75 \mathrm{mmHg}$ or $\mathrm{mMAP}_{24} \geq 75 \mathrm{mmHg}(57.0 \%$ vs. $29.8 \%$ vs. $26.9 \%, p<0.001$ for $\mathrm{mMAP}_{24}<65 \mathrm{mmHg}$ vs. other groups and $p=0.36$ between other groups). The $\mathrm{mMAP}_{24}$ was inversely associated with hospital mortality (unadjusted OR 0.82 per $5 \mathrm{mmHg}$ higher mMAP $_{24}, 95 \%$ CI $0.76-0.88, p<0.001$; optimal cutoff $64.6 \mathrm{mmHg}$; Fig. 2). Similar findings were observed in patients with ACS or HF (Supplemental Figures 2A and 2B), patients with CA (Supplemental Figures $3 \mathrm{~A}$ and $3 B)$, patients with a pre-admission diagnosis of hypertension (Supplemental Figures $4 \mathrm{~A}$ and $4 \mathrm{~B}$ ), and patients aged 65 years and older (Supplemental Figure 5). Mean values of systolic, diastolic, and mean BP were significantly lower for inpatient deaths at all time points $(1,6$, and $24 \mathrm{~h}$ ), although the magnitude of these differences was relatively modest (Supplemental Figure 6). The association between mMAP $_{24}$ and mortality remained after excluding patients with SCAI stages A and B of CS (adjusted OR 0.850 per $5 \mathrm{mmHg}$ higher, 95\% CI $0.755-$ 0.957, $p=0.007$ ), as well as in the overall cohort after adjusting for SCAI CS stage (adjusted OR 0.913 per 5 $\mathrm{mmHg}$, 95\% CI 0.838-0.994, $p=0.035$ ). The association between mMAP $_{24}$ and hospital mortality persisted after excluding patients with an admission diagnosis of sepsis (adjusted OR 0.873, 95\% CI 0.794-0.960, $p=0.0052$ ). The association between mMAP $_{24}$ and hospital mortality was present in patients without sepsis (adjusted OR $0.873,95 \%$ CI $0.794-0.960, p=0.0052$ ). The optimal mMAP $_{24}$ cutoff for predicting hospital mortality was $65.2 \mathrm{mmHg}$ in patients with ACS and $70.0 \mathrm{mmHg}$ in patients with HF. Hospital mortality varied as a function of $\mathrm{mMAP}_{24}$ and the maximum number of vasopressors during the first $24 \mathrm{~h}$ and the peak VIS during the first $24 \mathrm{~h}$ (Fig. 3). In subgroups of patients with and without a diagnosis of hypertension, there was no association 
Table 1 Baseline characteristics of the study population. Data represented as mean \pm standard deviation for continuous variables and $n(\%)$ for categorical variables

\begin{tabular}{|c|c|c|c|c|c|}
\hline & Overall $(n=1002)$ & MAP $<65 \mathrm{mmHg}(n=186)$ & MAP $65-75 \mathrm{mmHg}(n=426)$ & MAP $\geq 75 \mathrm{mmHg}(n=390)$ & $p$ value \\
\hline \multicolumn{6}{|l|}{ Demographics } \\
\hline Age & $67.7 \pm 13.8$ & & & & \\
\hline Female gender & $365(36.4 \%)$ & $75(40.3 \%)$ & $156(36.6 \%)$ & $134(34.4 \%)$ & 0.38 \\
\hline White race & $921(91.9 \%)$ & $173(93.0 \%)$ & $385(90.4 \%)$ & $363(93.1 \%)$ & 0.31 \\
\hline Body mass index & $29.3 \pm 6.8$ & $29.9 \pm 8.1$ & $29.1 \pm 6.4$ & $29.5 \pm 6.6$ & 0.59 \\
\hline \multicolumn{6}{|l|}{ Severity of illness } \\
\hline APACHE-III score & $86.2 \pm 33.0$ & $100.8 \pm 35.3$ & $87.5 \pm 32.0$ & $77.9 \pm 30.2$ & $<0.0001$ \\
\hline APACHE-IV predicted mortality & $0.38 \pm 0.29$ & $0.48 \pm 0.29$ & $0.40 \pm 0.29$ & $0.32 \pm 0.28$ & $<0.0001$ \\
\hline SOFA score & $7.6 \pm 4.2$ & $9.5 \pm 4.4$ & $7.9 \pm 4.1$ & $6.4 \pm 3.8$ & $<0.0001$ \\
\hline Maximum week 1 SOFA score & $8.4 \pm 4.2$ & $10.0 \pm 4.4$ & $8.7 \pm 4.1$ & $7.3 \pm 3.9$ & $<0.0001$ \\
\hline Cardiovascular SOFA score & $2.5 \pm 1.3$ & $3.0 \pm 1.2$ & $2.6 \pm 1.2$ & $2.1 \pm 1.3$ & $<0.0001$ \\
\hline \multicolumn{6}{|l|}{ Comorbidities } \\
\hline Charlson Comorbidity Index & $2.4 \pm 2.5$ & $2.84 \pm 2.7$ & $2.4 \pm 2.5$ & $2.1 \pm 2.4$ & 0.01 \\
\hline Prior myocardial infarction & $200(20.0 \%)$ & $35(18.8 \%)$ & $95(22.4 \%)$ & 70 (18.1\%) & 0.29 \\
\hline Prior heart failure & $193(19.4 \%)$ & $48(25.8 \%)$ & $90(21.2 \%)$ & $55(14.3 \%)$ & 0.002 \\
\hline Prior hypertension & $348(34.7 \%)$ & $64(34.4 \%)$ & $145(34.0 \%)$ & $139(35.6 \%)$ & 0.89 \\
\hline Prior diabetes mellitus & $287(28.8 \%)$ & $60(32.3 \%)$ & $119(28.0 \%)$ & $108(28.0 \%)$ & 0.51 \\
\hline Prior CKD & $202(20.2 \%)$ & $49(26.3 \%)$ & $82(19.3 \%)$ & $71(18.4 \%)$ & 0.07 \\
\hline Prior dialysis & $88(8.8 \%)$ & $32(17.2 \%)$ & $34(8.0 \%)$ & $22(5.6 \%)$ & 0.0001 \\
\hline Prior stroke & $121(12.1 \%)$ & $23(12.4 \%)$ & $58(13.7 \%)$ & $40(10.4 \%)$ & 0.36 \\
\hline Prior cancer & $214(21.5 \%)$ & $54(29.0 \%)$ & $97(22.8 \%)$ & $63(16.3 \%)$ & 0.002 \\
\hline \multicolumn{6}{|l|}{ Admission diagnoses } \\
\hline Cardiac arrest & $379(37.8 \%)$ & $63(33.9 \%)$ & $149(35.0 \%)$ & $167(42.8 \%)$ & 0.03 \\
\hline Sepsis & 199 (19.9\%) & $46(24.7 \%)$ & $96(22.5 \%)$ & $57(14.6 \%)$ & 0.003 \\
\hline Respiratory failure & $645(64.4 \%)$ & $115(61.8 \%)$ & $288(67.6 \%)$ & $242(62.1 \%)$ & 0.18 \\
\hline Acute coronary syndrome & $599(59.8 \%)$ & $98(52.7 \%)$ & $260(61.0 \%)$ & $241(61.8 \%)$ & 0.09 \\
\hline Heart failure & $740(73.9 \%)$ & $139(74.7 \%)$ & $326(76.5 \%)$ & $275(70.5 \%)$ & 0.14 \\
\hline \multicolumn{6}{|l|}{ SCAl cardiogenic shock stage } \\
\hline Stage A & $151(15.1 \%)$ & $7(3.8 \%)$ & $63(14.8 \%)$ & $81(20.8 \%)$ & $<0.0001$ \\
\hline Stage B & $336(33.5 \%)$ & $50(26.9 \%$ & $146(34.3 \%)$ & $140(35.9 \%)$ & $<0.0001$ \\
\hline Stage C & $116(11.6 \%)$ & $19(10.2 \%)$ & $41(9.6 \%)$ & $56(14.4 \%)$ & $<0.0001$ \\
\hline Stage D & $329(32.8 \%)$ & $84(45.2 \%)$ & $150(35.2 \%)$ & $95(24.4 \%)$ & $<0.0001$ \\
\hline Stage E & $70(7.0 \%)$ & $26(14.0 \%)$ & $26(6.1 \%)$ & $18(4.6 \%)$ & $<0.0001$ \\
\hline \multicolumn{6}{|l|}{ CICU admission clinical parameters } \\
\hline $\begin{array}{l}\text { Heart rate } \\
\text { (HR, beats per minute) }\end{array}$ & $90.7 \pm 24.1$ & $93.8 \pm 26.8$ & $91.3 \pm 23.7$ & $88.6 \pm 22.9$ & 0.09 \\
\hline $\begin{array}{l}\text { Systolic blood pressure } \\
\text { (SBP, mmHg) }\end{array}$ & $110.8 \pm 27.8$ & $97.0 \pm 24.0$ & $105.9 \pm 23.6$ & $120.0 \pm 30.6$ & $<0.0001$ \\
\hline $\begin{array}{l}\text { Diastolic blood pressure } \\
(\mathrm{mmHg})\end{array}$ & $65.3 \pm 18.8$ & $56.9 \pm 15.9$ & $63.9 \pm 17.0$ & $71.8 \pm 19.7$ & $<0.0001$ \\
\hline $\begin{array}{l}\text { Mean arterial pressure } \\
\text { (first } 24 \mathrm{~h}, \mathrm{mmHg} \text { ) }\end{array}$ & $73.4 \pm 10.1$ & $68.5 \pm 18.0$ & $76.9 \pm 17.3$ & $87.4 \pm 20.9$ & $<0.0001$ \\
\hline Shock index (HR/SBP) & $0.86 \pm 0.30$ & $1.0 \pm 0.31$ & $0.87 \pm 0.3$ & $0.79 \pm 0.9$ & $<0.0001$ \\
\hline Oxygen saturation (\%) & $92.9 \pm 10.9$ & $91.3 \pm 12.1$ & $92.6 \pm 11.6$ & $93.9 \pm 9.2$ & 0.006 \\
\hline
\end{tabular}


Table 1 Baseline characteristics of the study population. Data represented as mean \pm standard deviation for continuous variables and $n(\%)$ for categorical variables (Continued)

\begin{tabular}{|c|c|c|c|c|c|}
\hline & Overall $(n=1002)$ & MAP < $65 \mathrm{mmHg}(n=186)$ & MAP $65-75 \mathrm{mmHg}(n=426)$ & MAP $\geq 75 \mathrm{mmHg}(n=390)$ & $p$ value \\
\hline \multicolumn{6}{|l|}{ Admission laboratory values } \\
\hline Sodium & $137.0 \pm 5.1$ & $137.1 \pm 5.9$ & $136.7 \pm 5.0$ & $137.3 \pm 4.8$ & 0.11 \\
\hline Potassium & $4.3 \pm 0.9$ & $4.4 \pm 0.9$ & $4.4 \pm 0.87$ & $4.3 \pm 0.8$ & 0.08 \\
\hline Bicarbonate & $21.2 \pm 5.2$ & $20.9 \pm 6.0$ & $21.0 \pm 5.1$ & $21.5 \pm 4.8$ & 0.18 \\
\hline Anion gap & $14.1 \pm 4.8$ & $16.4 \pm 6.0$ & $13.7 \pm 4.8$ & $13.8 \pm 4.0$ & $<0.0001$ \\
\hline Creatinine & $1.6 \pm 1.1$ & $2.2 \pm 1.6$ & $1.5 \pm 1.0$ & $1.3 \pm 0.8$ & $<0.0001$ \\
\hline Hemoglobin & $12.1 \pm 2.4$ & $11.1 \pm 2.1$ & $12.0 \pm 2.3$ & $12.7 \pm 2.4$ & $<0.0001$ \\
\hline Lactate & $3.9 \pm 3.7$ & $5.1 \pm 4.6$ & $3.6 \pm 3.4$ & $3.7 \pm 3.4$ & 0.009 \\
\hline Troponin (initial) & $2.3 \pm 4.5$ & $2.7 \pm 6.6$ & $2.2 \pm 4.2$ & $2.1 \pm 3.8$ & 0.48 \\
\hline $\begin{array}{l}\text { Troponin } \\
\text { (peak during hospital stay) }\end{array}$ & $3.9 \pm 6.7$ & $4.5 \pm 8.9$ & $3.9 \pm 6.8$ & $3.7 \pm 5.4$ & 0.57 \\
\hline \multicolumn{6}{|l|}{ Procedures and therapies } \\
\hline Number of vasoactive drugs & $1.5 \pm 1.3$ & $2.0 \pm 1.4$ & $1.6 \pm 1.2$ & $1.1 \pm 1.3$ & $<0.0001$ \\
\hline Vasopressors & $722(72.1 \%)$ & $161(86.6 \%)$ & $332(77.9 \%)$ & $229(58.7 \%)$ & $<0.0001$ \\
\hline Inotropes & $282(28.1 \%)$ & $68(36.6 \%)$ & $123(28.9 \%)$ & $91(23.3 \%)$ & $<0.0001$ \\
\hline $\begin{array}{l}\text { Peak vasoactive infusion score } \\
\text { (VIS) }\end{array}$ & $26.1 \pm 54.3$ & $47.6 \pm 79.0$ & $23.8 \pm 46.3$ & $18.5 \pm 44.7$ & $<0.0001$ \\
\hline Invasive ventilation & $599(59.8 \%)$ & $105(56.5 \%)$ & $269(63.2 \%)$ & $225(57.7 \%)$ & 0.17 \\
\hline Noninvasive ventilation & $241(24.1 \%)$ & $42(22.6 \%)$ & $118(27.7 \%)$ & $81(20.8 \%)$ & 0.06 \\
\hline Dialysis & $101(10.1 \%)$ & $27(14.5 \%)$ & $43(10.1 \%)$ & $31(8.0 \%)$ & 0.05 \\
\hline Intra-aortic balloon pump & $389(38.8 \%)$ & $41(22.0 \%)$ & $193(45.3 \%)$ & 155 (39.7\%) & $<0.0001$ \\
\hline Pulmonary artery catheter & $240(24.0 \%)$ & $40(21.5 \%)$ & $112(26.3 \%)$ & $88(22.6 \%)$ & 0.32 \\
\hline Coronary angiogram & $647(64.6 \%)$ & 97 (52.2\%) & $275(64.6)$ & 275 (70.5\%) & $<0.0001$ \\
\hline $\begin{array}{l}\text { Percutaneous coronary } \\
\text { intervention }\end{array}$ & $325(32.4 \%)$ & $48(25.8 \%)$ & $142(33.3 \%)$ & $135(34.6 \%)$ & 0.09 \\
\hline Impella ${ }^{\oplus}$ & $8(0.8 \%)$ & $2(1.1 \%)$ & $5(1.2 \%)$ & $1(0.3 \%)$ & 0.25 \\
\hline ECMO & $2(0.2 \%)$ & $0(0 \%)$ & $0(0 \%)$ & $2(0.5 \%)$ & 0.21 \\
\hline \multicolumn{6}{|l|}{ Outcomes } \\
\hline $\begin{array}{l}\text { Severe acute kidney injury } \\
\text { during CICU stay }\end{array}$ & $314(36.5 \%)$ & $63(46.0 \%)$ & $139(36.7 \%)$ & $112(32.5 \%)$ & 0.02 \\
\hline $\begin{array}{l}\text { Severe acute kidney injury } \\
\text { during hospital }\end{array}$ & $392(43.6 \%)$ & 71 (49.3\%) & $172(44.1 \%)$ & 149 (40.9\%) & 0.22 \\
\hline CICU length of stay & $4.3 \pm 7.3$ & $4.5 \pm 14.1$ & $4.6 \pm 4.8$ & $3.8 \pm 3.8$ & $<0.0001$ \\
\hline Hospital length of stay & $13.1 \pm 18.1$ & $14.4 \pm 25.4$ & $13.7 \pm 18.5$ & $11.7 \pm 12.5$ & 0.02 \\
\hline CICU mortality & $234(23.3 \%)$ & 80 (43.0\%) & $81(19.0 \%)$ & $73(18.7 \%)$ & $<0.0001$ \\
\hline Hospital mortality & $338(33.7 \%)$ & $106(57.0 \%)$ & $127(29.8 \%)$ & 105 (26.9\%) & $<0.0001$ \\
\hline
\end{tabular}

APACHE Acute Physiology And Chronic Health Evaluation, BUN blood urea nitrogen, CICU cardiac intensive care unit, CKD chronic kidney disease, ECMO extracorporeal membrane oxygenation, IABP intra-aortic balloon pump, RBC red blood cell, SCAI Society for Cardiovascular Angiography and Interventions, SOFA Sequential Organ Failure Assessment, WBC white blood cell

between mMAP $_{24}$ and the incidence of severe $\operatorname{AKI}(p=$ 0.83) (Supplemental Figures 4A and 4B).

After multivariable adjustment, $\mathrm{mMAP}_{24}$ remained inversely associated with hospital mortality (adjusted OR 0.89 per $5 \mathrm{mmHg}$ higher $\mathrm{mMAP}_{24}, 95 \%$ CI $0.82-0.97$, $p=0.01$, Table 2). Patients with a $\mathrm{mMAP}_{24}<65 \mathrm{mmHg}$ were at higher risk of hospital mortality (adjusted OR 2.05, 95\% CI 1.38-3.02, $p<0.001$ ), with no difference between patients with mMAP $_{24} \quad 65-75 \mathrm{mmHg}$ and $\operatorname{mMAP}_{24} \geq 75 \mathrm{mmHg}(p=0.77)$.

\section{Discussion}

In this retrospective study of a large tertiary CICU patient population with $\mathrm{CS}$, we demonstrate that $\mathrm{mMAP}_{24}$ is inversely associated with $\mathrm{CICU}$ and hospital mortality after adjusting for illness severity and CICU therapies, 
A
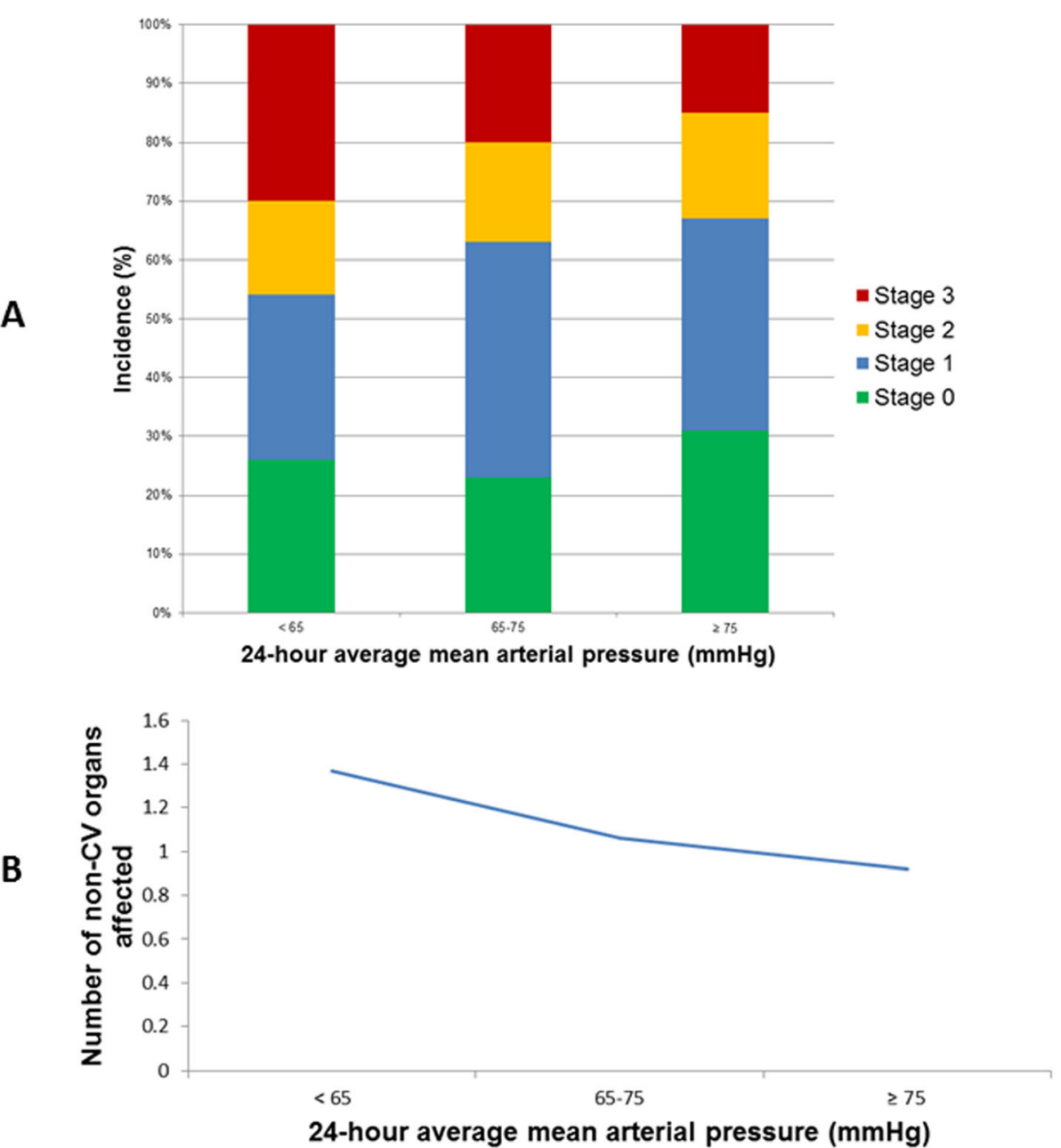

Fig. $\mathbf{1}$ a, $\mathbf{b}$ Incidence of acute kidney injury by stage (a) and non-cardiac organ failure (by number of organs affected, $\mathbf{b}$ ) as a function of the 24-h average mean arterial pressure $\left(\mathrm{mMAP}_{24}\right)$

including patients with common $\mathrm{CICU}$ diagnoses such as ACS, HF, and CA. These data suggest that MMAP $_{24}$ is an independent predictor of hospital mortality in CS patients across subgroups, even when accounting for vasopressor requirements. The association between $\mathrm{mMAP}_{24}$ and hospital mortality remained even after adjustment for the SCAI shock stage, suggesting that the importance of $\mathrm{mMAP}_{24}$ extends beyond initial shock severity alone. Patients who were able to maintain a MAP above $65 \mathrm{mmHg}$ had lower hospital mortality; similar results were seen among patients with ACS, whereas unexpectedly patients with $\mathrm{HF}$ seemed to have better outcomes at a MAP above $70 \mathrm{mmHg}$. Among patients with a MAP below $65 \mathrm{mmHg}$, hospital mortality increased in proportion to the severity of hypotension, and patients with the most severe hypotension were at highest risk of mortality. We observed a threshold effect, such that patients with progressively higher mMAP $_{24}$ above these levels did not have further decreases in mortality. The prevalence of non-cardiovascular organ failure and severe AKI was higher among patients with lower MAP, potentially explaining why these patients had higher mortality. Notably, not all patients who had an admission diagnosis of CS received vasopressors, mechanical circulatory support, or had manifest hypoperfusion on CICU admission, suggesting that some patients had resolved CS. These data suggest that maintaining MAP goals lower than $65 \mathrm{mmHg}$ may not be adequate to preserve organ perfusion. However, targeting MAP goals higher than $65 \mathrm{mmHg}$ may potentially expose patients to added hazards from the known adverse effects of vasoactive drugs without definite benefit. We did not observe a difference in MAP thresholds in patients with a pre-existing history of hypertension, and our findings do not suggest that a higher MAP is preferentially associated with any decrease in mortality or end-organ injury among this subgroup of patients. 


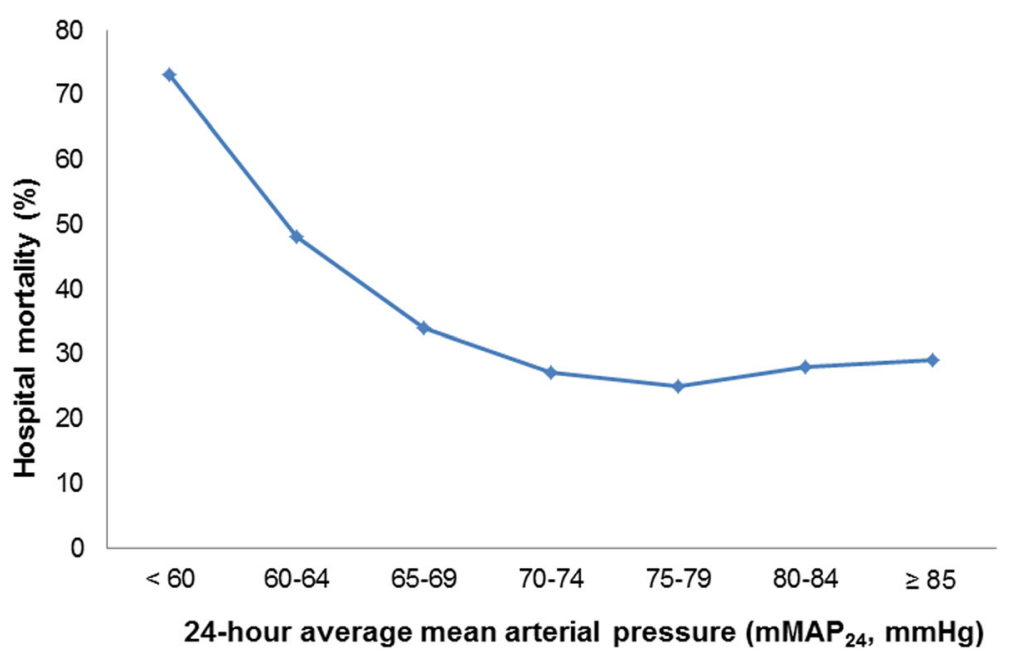

Fig. 2 Hospital mortality as a function of the average mean arterial pressure in the first $24 \mathrm{~h}$ of cardiac intensive care unit (CICU) admission $\left(\mathrm{mMAP}_{24}\right)$

Evidence-based therapies available to patients with CS remain limited, and much of the critical care strategies in the CICU have been extrapolated from other non-CS populations [3]. The optimal MAP goal in patients with CS has not been well defined. Current strategies are based on evidence from patients with other forms of circulatory shock, particularly patients with sepsis whose physiology is entirely different from CS due to the presence of a low diastolic blood pressure from vasoplegia which drives down the MAP $[7,18]$. The SEPSISPAM trial compared a vasopressor strategy targeting MAP of $80-85 \mathrm{mmHg}$ to a target of $65-70 \mathrm{mmHg}$ in patients with septic shock and found no difference in death or AKI at 28 days despite more arrhythmias in the higher MAP arm; patients with chronic hypertension maintained at the higher MAP target were less likely to suffer from AKI [7]. By contrast, a recent multicenter randomized controlled trial of patients 65 years and older who were admitted to the ICU with septic shock demonstrated that permissive hypotension (MAP 60-65

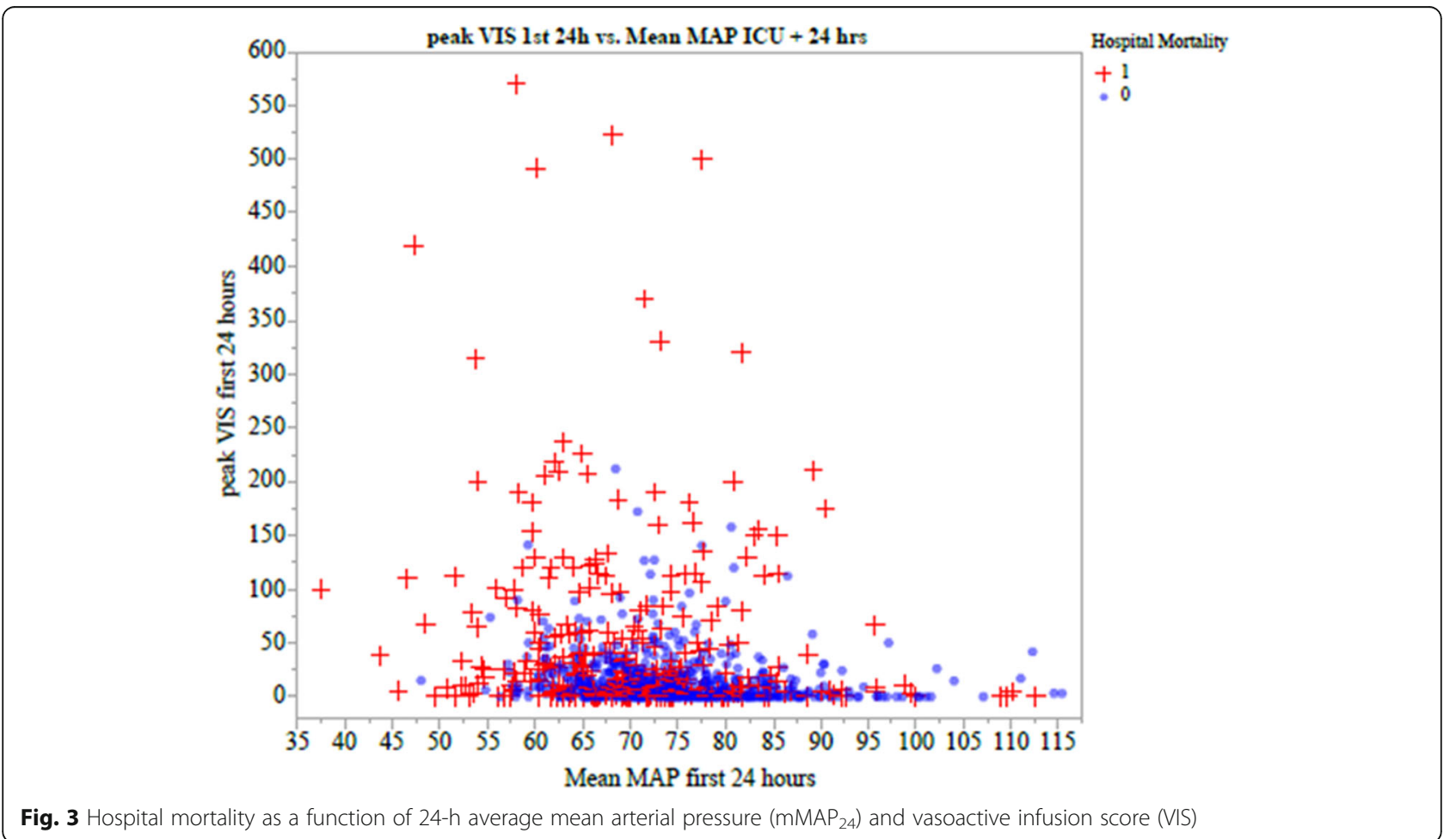


Table 2 Predictors of hospital mortality on multivariable regression. Only predictors with $p<0.1$ are shown. Additional predictors with $p \geq 0.1$ included in the model were white race, noninvasive ventilator use, creatinine, hemoglobin, PAC, RBC transfusion, respiratory failure, HF, and sepsis. Final model validation AUC 0.80

\begin{tabular}{llll}
\hline Variable & Adjusted OR & $95 \% \mathrm{Cl}$ & $p$ value \\
\hline APACHE-IV predicted mortality & 3.61 & $1.81-7.22$ & $<0.001$ \\
Cardiac arrest & 3.11 & $2.21-4.36$ & $<0.001$ \\
Dialysis during CICU admission & 2.64 & $1.68-4.14$ & $<0.001$ \\
mMAP $_{24}<65 \mathrm{mmHg}$ & 2.05 & $1.38-3.02$ & $<0.001$ \\
Charlson Comorbidity Index & 1.07 & $1.01-1.14$ & 0.03 \\
Age (per year) & 1.03 & $1.02-1.04$ & $<0.001$ \\
Peak vasoactive infusion score (VIS) during first 24h & 1.01 & $1.01-1.02$ & 0.02 \\
IABP & 0.64 & $0.44-0.92$ & 0.02 \\
\hline
\end{tabular}

Abbreviations: APACHE Acute Physiology and Chronic Health Evaluation, IABP intra-aortic balloon pump, $m M A P_{24}$ average mean arterial pressure (MAP) in the first $24 \mathrm{~h}$

$\mathrm{mmHg}$ ) reduced vasopressor exposure without increasing the risk of mortality or AKI (including patients with and without hypertension) [9]. The findings of our study indirectly support the safety of a lower MAP target (i.e., 65-70 $\mathrm{mmHg}$ ) in CS patients, but did not show a benefit of higher MAP targets among patients with a history of hypertension. Evidence supports the use of vasopressors such as norepinephrine that have a lower rate of cardiovascular adverse events, including increased myocardial oxygen demand, ischemia, arrhythmias, and mortality [1, 14]. In general, increasing doses of vasoactive agents increase the risk of cardiovascular adverse events and are associated with higher mortality, and current recommendations suggest the lowest effective dose necessary to achieve a target MAP [3, 14]. We observed a strong independent association between higher vasopressor doses based on $\mathrm{VIS}_{24}$ and higher hospital mortality.

Many CS patients are already maximally vasoconstricted due to cardiac pump failure, and further increasing afterload with vasopressors may be deleterious, particularly when targeting higher MAP goals [3]. In the distinct high-risk subgroup of patients with CA, which is commonly associated with abnormal cerebral blood flow autoregulation, retrospective evidence suggests that maintenance of a higher MAP may be considered to improve cerebral perfusion and neurological outcomes [6]. However, randomized controlled trials of higher MAP targets ( 80 or 85 to $100 \mathrm{mmHg}$ ) have not shown an improvement in neurological outcomes when compared to a target of $65 \mathrm{mmHg}[18,19]$. Likewise, we did not observe a different MAP threshold for patients with CA and CS in our study. The use of higher vasopressor doses to achieve a higher target MAP after CA poses a risk of increasing the arrhythmia burden, which may be particularly harmful in CA patients with an arrhythmic substrate. As a result, current society guidelines for patients with septic shock or CA recommend MAP targets of $65-70 \mathrm{mmHg}[6,20]$.
It is crucial to note that the observed association between outcomes and mMAP $_{24}$ demonstrated in our retrospective observational study is not the same as testing specific MAP goals for titrating vasopressor therapy in CS patients. We could not determine the MAP goals used by the treatment team, and therefore, we could not distinguish patients who had low MAP due to failure to achieve a prescribed MAP goal from those in whom a lower MAP was successfully targeted. Besides, patients with lower MAP had more severe illness by all relevant metrics and did not receive as many supportive cardiovascular procedures; we could not exclude the possibility that these patient-specific factors drove the adverse outcomes as opposed to the lower MAP itself. Importantly, CS patients may preferentially benefit from tailored vasopressor and inotropic support guided by hemodynamic data, such as those derived from a pulmonary artery catheter, rather than a "one-size-fits-all" approach [3]. Nonetheless, our data clearly show that an inability to maintain MAP $\geq 65 \mathrm{mmHg}$ during the first $24 \mathrm{~h}$ after CICU admission is associated with adverse outcomes in CICU patients with CS.

\section{Limitations}

This retrospective cohort study has a number of inherent limitations, including the potential for unmeasured confounders and missing data to have influenced the results. This single-center cohort may not fully represent the general patient population with CS. The mMAP $_{24}$ values included both invasive and noninvasive MAP measurements, but we could not determine which MAP measurements were made using each method, and $\mathrm{mMAP}_{24}$ potentially included a mixture of both. Admission diagnoses are based on ICD-9 coding and may underrepresent the number of patients with $\mathrm{CS}$ and associated comorbidities. The inclusion of a mixed CICU population without available hemodynamic or echocardiographic data implies that some patients may have had 
non-cardiogenic or mixed cardiogenic-septic shock states. MAP data is limited to the first $24 \mathrm{~h}$ of $\mathrm{CICU}$ admission, so this study cannot evaluate the association between patient outcomes and MAP beyond 24 $h$. For this reason, we specifically focused on organ failure occurring during the first $24 \mathrm{~h}$ of CICU admission and cannot comment on later development of organ failure. Detailed data regarding vasopressor doses over time could potentially provide additional indication of illness severity in the context of $\mathrm{mMAP}_{24}$; unfortunately, these data were not available. Patients with mMAP $_{24}<65 \mathrm{mmHg}$ were less likely to undergo PCI; the reasons for this are likely multifactorial and largely dependent on clinical factors and contraindications (e.g., severe shock, renal injury, or concern for cerebral anoxia). Unfortunately, our retrospective dataset cannot account for these clinical decisions. In addition, we could not determine the incidence of relevant cardiovascular adverse events attributable to vasopressor and inotrope therapy. Due to lack of data availability, we could not account for patient-level variables before CICU admission, including specific diagnostic or therapeutic interventions which took place before CICU admission.

\section{Conclusions}

There was an inverse correlation between mMAP in the first $24 \mathrm{~h}$ and hospital mortality among patients with CS admitted to the CICU. Patients with a MAP below $65 \mathrm{mmHg}$ during the first $24 \mathrm{~h}$ after $\mathrm{CICU}$ admission had an increased risk of mortality. These findings provide indirect support for a MAP target of $65 \mathrm{mmHg}$ for most CICU patients with CS. Further prospective research should evaluate which, if any, MAP goals are optimal for patients with specific hemodynamic or etiologic subtypes of CS.

\section{Supplementary information}

Supplementary information accompanies this paper at https://doi.org/10. 1186/s13054-020-03217-6.

Additional file 1: Supplemental Figure 1. Patient flow diagram describing inclusion/exclusion criteria and patient groups. Supplemental Figure $\mathbf{2} \mathbf{A B}$. Hospital mortality as a function of the 24-hour average mean arterial pressure $\left(\mathrm{mMAP}_{24}\right)$, among patients with acute coronary syndrome (A) or heart failure (B). Supplemental Figure 3AB. Hospital mortality and incidence of severe acute kidney injury (AKI) as a function of the 24-hour average mean arterial pressure $\left(\mathrm{MMAP}_{24}\right)$, among patients with (A) and without (B) cardiac arrest. Supplemental Figure 4AB. Hospital mortality and incidence of severe acute kidney injury (AKI) as a function of the 24-hour average mean arterial pressure $\left(\mathrm{mMAP}_{24}\right)$, among patients with (A) and without (B) a pre-admission diagnosis of hypertension. Supplemental Figure 5. Hospital mortality as a function of the 24hour average mean arterial pressure $\left(\mathrm{mMAP}_{24}\right)$, among patients age 65 and older. Supplemental Figure 6. Mean values of systolic (circles), diastolic (arrows), and mean (diamonds) blood pressure over the first 1, 6, and 24 hours of the CICU stay.

\section{Abbreviations}

ACS: Acute coronary syndrome; AKI: Acute kidney injury; CA: Cardiac arrest: CICU: Cardiac intensive care unit; CS: Cardiogenic shock; HF: Heart failure; MAP: Mean arterial pressure; $\mathrm{mMAP}_{24}$ : Average mean arterial pressure during first $24 \mathrm{~h}$ of $\mathrm{CICU}$ admission

\section{Authors' contributions}

JCJ helped conceive of the study, designed the data analysis plan, acquired the data, performed the statistical analysis, and drafted the manuscript. BB helped conceive of the study, assisted with the analysis, and drafted the manuscript. MT, GWB, MRB, and KK contributed to the data analysis and drafting of the manuscript. All authors were involved in the data interpretation and manuscript revision for intellectual content. All authors have provided approval of the final manuscript.

\section{Funding}

None declared.

\section{Availability of data and materials}

The dataset supporting the conclusions of this article is included within the article and its supplementary materials.

\section{Ethics approval and consent to participate}

This study was approved by the Institutional Review Board of Mayo Clinic (IRB \# 16-000722) as posing minimal risk to patients and was performed under a waiver of informed consent.

\section{Consent for publication}

Not applicable.

\section{Competing interests}

The authors declare that they have no competing interests.

\section{Author details}

'Division of Pulmonary and Critical Care Medicine, Mayo Clinic, Rochester, MN, USA. ${ }^{2}$ Department of Cardiovascular Medicine, Mayo Clinic, Rochester, MN, USA. ${ }^{3}$ Division of Nephrology and Hypertension, Mayo Clinic, Rochester, MN, USA. ${ }^{4}$ Department of Internal Medicine, Mayo Clinic, 200 First Street SW, Rochester, MN 55905, USA.

Received: 26 April 2020 Accepted: 29 July 2020

Published online: 20 August 2020

\section{References}

1. De Backer D, Biston P, Devriendt J, Madl C, Chochrad D, Aldecoa C, Brasseur A, Defrance $P$, Gottignies P, Vincent J-L, et al. Comparison of dopamine and norepinephrine in the treatment of shock. N Engl J Med. 2010;362(9):779-89.

2. Berg DD, Bohula EA, van Diepen S, Katz JN, Alviar CL, Baird-Zars VM, Barnett CF, Barsness GW, Burke JA, Cremer PC, et al. Epidemiology of shock in contemporary cardiac intensive care units. Circ Cardiovasc Qual Outcomes. 2019;12(3):e005618.

3. van Diepen S, Katz JN, Albert NM, Henry TD, Jacobs AK, Kapur NK, Kilic A, Menon V, Ohman EM, Sweitzer NK, et al. Contemporary management of cardiogenic shock: a scientific statement from the American Heart Association. Circulation. 2017;136(16):e232-68.

4. Amsterdam EA, Wenger NK, Brindis RG, Casey DE Jr, Ganiats TG, Holmes DR Jr, Jaffe AS, Jneid H, Kelly RF, Kontos MC, et al. 2014 AHA/ACC guideline for the management of patients with non-ST-elevation acute coronary syndromes a report of the American College of Cardiology/American Heart Association task force on practice guidelines. Circulation. 2014;130(25):E344-426.

5. Werdan K, Russ M, Buerke M, Delle-Karth G, Geppert A, Schoendube FA. Cardiogenic shock due to myocardial infarction: diagnosis, monitoring and treatment a German-Austrian S3 guideline. Deutsches Arzteblatt International. 2012;109(19):343-U315.

6. Callaway CW, Donnino MW, Fink EL, Geocadin RG, Golan E, Kern KB, Leary M, Meurer WJ, Peberdy MA, Thompson TM, et al. Part 8: post-cardiac arrest care: 2015 American Heart Association guidelines update for cardiopulmonary resuscitation and emergency cardiovascular care. Circulation. 2015;132(18 Suppl 2):S465-82. 
7. Asfar P, Meziani F, Hamel J-F, Grelon F, Megarbane B, Anguel N, Mira J-P, Dequin P-F, Gergaud S, Weiss N, et al. High versus low blood-pressure target in patients with septic shock. N Engl J Med. 2014;370(17):1583-93.

8. Heart Outcomes Prevention Evaluation Study I, Yusuf S, Sleight P, Pogue J, Bosch J, Davies R, Dagenais G. Effects of an angiotensin-converting-enzyme inhibitor, ramipril, on cardiovascular events in high-risk patients. N Engl J Med. 2000;342(3):145-53.

9. Lamontagne F, Richards-Belle A, Thomas K, Harrison DA, Sadique MZ, Grieve RD, Camsooksai J, Darnell R, Gordon AC, Henry D et al: Effect of reduced exposure to vasopressors on 90-day mortality in older critically ill patients with vasodilatory hypotension. JAMA. 2020;323(10):938-49. https://doi.org/ 10.1001/jama.2020.0930. Online ahead of print.

10. Jentzer JC, Bennett C, Wiley BM, Murphree DH, Keegan MT, Gajic O, Wright RS, Barsness GW: Predictive value of the sequential organ failure assessment score for mortality in a contemporary cardiac intensive care unit population. J Am Heart Assoc. 2018;7(6):e008169. https://doi.org/10.1161/JAHA.117.008169.

11. Jentzer JC, Murphree DH, Wiley B, Bennett C, Goldfarb M, Keegan MT, Murphy JG, Wright RS, Barsness GW. Comparison of mortality risk prediction among patients $>/=70$ versus $<70$ years of age in a cardiac intensive care unit. Am J Cardiol. 2018;122(10):1773-8.

12. Bennett CE, Wright RS, Jentzer J, Gajic O, Murphree DH, Murphy JG, Mankad SV, Wiley BM, Bell MR, Barsness GW. Severity of illness assessment with application of the APACHE IV predicted mortality and outcome trends analysis in an academic cardiac intensive care unit. J Crit Care. 2018:50:242-6.

13. Herasevich V, Pickering BW, Dong Y, Peters SG, Gajic O. Informatics infrastructure for syndrome surveillance, decision support, reporting, and modeling of critical illness. Mayo Clin Proc. 2010;85(3):247-54.

14. Jentzer JC, Wiley B, Bennett C, Murphree DH, Keegan MT, Kashani KB, Bell MR, Barsness GW. Temporal trends and clinical outcomes associated with vasopressor and inotrope use in the cardiac intensive care unit. Shock. 2020; 53(4):452-9.

15. Brueske B, Sidhu MS, Schulman-Marcus J, Kashani KB, Barsness GW, Jentzer JC. Hyperkalemia is associated with increased mortality among unselected cardiac intensive care unit patients. J Am Heart Assoc. 2019;8(7):e011814.

16. Jentzer JC, Wiley B, Bennett C, Murphree DH, Keegan MT, Gajic O, Kashani $\mathrm{KB}$, Barsness GW: Early noncardiovascular organ failure and mortality in the cardiac intensive care unit. Clin Cardiol. 2020;43(5):516-23. https://doi.org/ 10.1002/clc.23339.

17. Rocca WA, Yawn BP, St Sauver UL, Grossardt BR, Melton LJ 3rd. History of the Rochester Epidemiology Project: half a century of medical records linkage in a US population. Mayo Clin Proc. 2012;87(12):1202-13.

18. Jakkula P, Pettila V, Skrifvars MB, Hastbacka J, Loisa P, Tiainen M, Wilkman E, Toppila J, Koskue T, Bendel S, et al. Targeting low-normal or high-normal mean arterial pressure after cardiac arrest and resuscitation: a randomised pilot trial. Intensive Care Med. 2018;44(12):2091-101.

19. Ameloot K, De Deyne C, Eertmans W, Ferdinande B, Dupont M, Palmers P Petit T, Nuyens P, Maeremans J, Vundelinckx J, et al. Early goal-directed haemodynamic optimization of cerebral oxygenation in comatose survivors after cardiac arrest: the Neuroprotect post-cardiac arrest trial. Eur Heart J. 2019:40(22):1804-14.

20. Rhodes A, Evans LE, Alhazzani W, Levy MM, Antonelli M, Ferrer R, Kumar A, Sevransky JE, Sprung CL, Nunnally ME, et al. Surviving Sepsis Campaign: international guidelines for management of sepsis and septic shock: 2016. Intensive Care Med. 2017;43(3):304-77.

\section{Publisher's Note}

Springer Nature remains neutral with regard to jurisdictional claims in published maps and institutional affiliations.

Ready to submit your research? Choose BMC and benefit from:

- fast, convenient online submission

- thorough peer review by experienced researchers in your field

- rapid publication on acceptance

- support for research data, including large and complex data types

- gold Open Access which fosters wider collaboration and increased citations

- maximum visibility for your research: over $100 \mathrm{M}$ website views per year

At $\mathrm{BMC}$, research is always in progress.

Learn more biomedcentral.com/submissions 